\title{
Dose Fractionation Effects in Primary and Metastatic Human Uveal Melanoma Cell Lines
}

\author{
Gerard J. M. J. van den Aardweg, ${ }^{1}$ Emine Kiliç, ${ }^{2}$ Annelies de Klein, ${ }^{3}$ and \\ Gregorius P. M. Luyten ${ }^{2}$
}

Purpose. To investigate the effects of split-dose irradiation on primary and metastatic uveal melanoma cell lines, with a clonogenic survival assay.

Methods. Appropriate cell concentrations of four primary and four metastatic human uveal melanoma cell lines were cultured for irradiation with single doses and with two equal fractions separated by 5 hours. After irradiation, colony formation was allowed for 7 to 21 days. Two cutaneous melanomas were also tested for comparison. All survival curves were analyzed using the linear quadratic (LQ) model. Specific parameters for the intrinsic radiosensitivity ( $\alpha$-component, $\mathrm{SF}_{2}$ ), for the capacity of repair of DNA damage ( $\beta$-component), as well as the $\alpha / \beta$ ratio were calculated.

Results. After single-dose irradiation a wide range in the values of the $\alpha$ - and $\beta$-component was obtained for both primary and metastatic uveal melanomas, which resulted in a wide range of $\alpha / \beta$ ratios. In contrast, calculations based on split-dose data, with which the $\beta$-component could be estimated independent of the $\alpha$-component, indicated that estimates for the capacity of sublethal DNA damage repair was very similar in all cell lines. This indicated that intrinsic factors dominated the radiosensitivity of these cell lines. Split-dose irradiation had little influence on the intrinsic radiosensitivity ( $\alpha$-component), but cell survival increased for all cell lines. For the two cutaneous melanomas comparable split-dose results were obtained.

Conclusions. For both primary and metastatic uveal melanoma cell lines, data from single and fractionated doses indicate large variations in radiosensitivity, which are mainly dominated by the intrinsic radiosensitivities. Doses of approximately $8 \mathrm{~Gy}$ in five fractions would be sufficient to eradicate $10^{9}$ cells (approximately $1 \mathrm{~cm}^{3}$ ) of the most radioresistant tumor cell lines, but this schedule is an overkill for the radiosensitive tumor cell lines. Based on specific morphologic and histologic tumor markers, more individualized dose fractionation schedules could improve the therapeutic ratio for uveal melanomas. (Invest Ophthalmol Vis Sci. 2003;44:4660-4664) DOI:10.1167/ iovs.03-0151

From the ${ }^{1}$ Department of Radiation Oncology, Division of Clinical Radiobiology, and the Departments of ${ }^{2}$ Ophthalmology and ${ }^{3}$ Clinical Genetics, Erasmus Medical Centre, Rotterdam, The Netherlands.

Supported by grants from The Dutch Foundation Fighting against Blindness, The Rotterdam Blindness Foundation, The Hague Ophthalmic Foundation and the Revolving Fund of the University Hospital Rotterdam.

Submitted for publication February 11, 2003; revised July 18, 2003; accepted July 23, 2003.

Disclosure: G.J.M.J. van den Aardweg, None; E. Kiliç, None; A. de Klein, None; G.P.M. Luyten, None

The publication costs of this article were defrayed in part by page charge payment. This article must therefore be marked "advertisement" in accordance with 18 U.S.C. $\$ 1734$ solely to indicate this fact.

Corresponding author: Gerard J. M. J. van den Aardweg, Department of Radiation Oncology, Subdivision of Clinical Radiobiology, Josephine Nefkens Institute, Erasmus MC/Daniel den Hoed Cancer Centre, Rotterdam, P.O. Box 1738, 3000 DR Rotterdam, The Netherlands; g.vandenaardweg@chello.nl.
For small and medium-sized uveal melanomas, radiotherapy is the first choice of treatment. Large-dose fractions of 10 to 12 Gy offer patients an eye- and vision-sparing alternative to enucleation. However, radiotherapy-related acute and late ocular complications have been reported. ${ }^{1,2}$ Reduction of these side effects and improvement of the therapeutic ratio could be achieved by a better understanding of the radiosensitivity and capacity for DNA damage repair of these tumors. So far, only limited information on the cellular radiosensitivity of uveal melanoma cell lines is available. ${ }^{3-5}$ In a recent publication large differences in the intrinsic cellular radiosensitivity were demonstrated for primary and metastatic human uveal melanoma cell lines. ${ }^{6}$ The data also pointed to large differences in the capacity for repair of radiation-induced DNA damage, justifying a more refined study with the use of split-dose irradiation.

In this article we present single-dose and split-dose data for cell survival curves analyzed with the linear quadratic (LQ) model. ${ }^{7-9}$ This provides information on the intrinsic radiosensitivity and repair capacity of these uveal melanoma cell lines. In the LQ model, the $\alpha$-component is regarded as a suitable parameter for the intrinsic radiosensitivity. An alternative way of expressing the radiosensitivity is the surviving fraction at 2 Gy $\left(\mathrm{SF}_{2}\right) \cdot{ }^{10-12}$ When a single dose of X-rays is divided into two fractions separated by an interval of several hours, an enhancement of survival occurs. The magnitude of this recovery, interpreted as a reflection of the repair of sublethal DNA damage induced by the first dose, can be expressed by the $\beta$-component in the LQ model.

\section{Materials ANd Methods}

\section{Cell Lines and Culture Conditions}

Four primary and four metastatic uveal melanoma cell lines were used throughout this study. Two cutaneous melanoma cell lines were also tested for comparison. Details of the cell lines and culture conditions have been described previously. ${ }^{6} \mathrm{~A}$ few adjustments were made in comparison with the previous study. Cells were plated with a range of increasing concentrations and incubated for 2 hours instead of overnight, to allow cell attachment before radiation commenced. Overnight incubation for cell attachment is not appropriate for cell lines with short doubling times, as indicated in this study. For some cell lines (OCM-1, 92-1, OMM-1, and Bowes) higher cell concentrations were also used in this study, particularly after the higher doses, to increase colony numbers and hence to obtain more reliable data

\section{Irradiation and Clonogenic Assay}

Technical details of the irradiation procedure and the colony assay have been described previously. ${ }^{6}$ Single doses of 0 to 10 Gy were given with one six-well plate per dose point containing two consecutive cell concentrations. In the dose fractionation experiment the total dose was split in two equal fractions with a time interval of 5 hours. An interval of 5 hours is sufficient for maximum repair of DNA damage without substantial cell cycle progression. ${ }^{13,14}$ For the split dose study a separate set of six-well plates was used again with one plate per dose point containing two consecutive cell concentrations. Both single and fractionated irradiations were performed in conjunction on the same 
TABLE 1. Parameters for Uveal and Cutaneous Melanomas after Single and Fractionated Doses of X-Irradiation

\begin{tabular}{|c|c|c|c|c|c|c|c|c|}
\hline Cell Type & Plating Eff. (\%) & $\begin{array}{l}\text { Cell-Doubling } \\
\text { Time (h) }\end{array}$ & $\alpha\left(G y^{-1}\right)$ & $\beta\left(G y^{-2}\right)$ & $\alpha / \beta(G y)$ & $\mathbf{S F}_{2}$ & $\beta_{\mathrm{RR}}\left(G \mathbf{G}^{-2}\right)$ & $\alpha / \beta_{\mathbf{R R}}(\mathbf{G y})$ \\
\hline \multicolumn{9}{|l|}{ Uveal melanoma } \\
\hline OCM-1 (100-6,400)* & $\begin{array}{l}29.4 \pm 2.3 \dagger \\
29.9 \pm 3.0 \neq\end{array}$ & $18.1 \pm 0.4$ & $\begin{array}{l}0.153 \\
0.154\end{array}$ & 0.047 & $3.5 \pm 0.5$ & $\begin{array}{l}0.61 \\
0.66\end{array}$ & 0.039 & 3.9 \\
\hline Mel $270(800-25,600)$ & $\begin{array}{l}9.4 \pm 1.0 \\
8.8 \pm 1.2\end{array}$ & $42.7 \pm 1.3$ & $\begin{array}{l}0.534 \\
0.451\end{array}$ & 0.027 & $20.8 \pm 1.6$ & $\begin{array}{l}0.31 \\
0.37\end{array}$ & 0.031 & 17.5 \\
\hline OMM 2-2 (200-6,400) & $\begin{array}{l}42.2 \pm 3.7 \\
43.1 \pm 2.7\end{array}$ & $28.7 \pm 1.6$ & $\begin{array}{l}0.436 \\
0.439\end{array}$ & 0.092 & $4.7 \pm 0.5$ & $\begin{array}{l}0.29 \\
0.34\end{array}$ & 0.048 & 9.2 \\
\hline OMM 2-3 (400-12,800) & $\begin{array}{l}18.5 \pm 4.1 \\
18.5 \pm 4.0\end{array}$ & $36.4 \pm 2.6$ & $\begin{array}{l}0.364 \\
0.341\end{array}$ & 0.039 & $10.3 \pm 1.6$ & $\begin{array}{l}0.41 \\
0.47\end{array}$ & 0.041 & 8.9 \\
\hline OMM 2-6 (400-12,800) & $\begin{array}{l}9.2 \pm 0.6 \\
9.6 \pm 0.6\end{array}$ & $35.2 \pm 1.7$ & $\begin{array}{l}0.330 \\
0.365\end{array}$ & 0.046 & $8.8 \pm 2.0$ & $\begin{array}{l}0.43 \\
0.45\end{array}$ & 0.034 & 9.6 \\
\hline Mel 202 (400-25,600) & $\begin{array}{l}32.1 \pm 2.8 \\
31.5 \pm 1.9\end{array}$ & $25.1 \pm 0.7$ & $\begin{array}{l}0.274 \\
0.250\end{array}$ & 0.035 & $10.3 \pm 3.0$ & $\begin{array}{l}0.50 \\
0.56\end{array}$ & 0.032 & 8.5 \\
\hline $92-1(400-51,200)$ & $\begin{array}{l}11.1 \pm 1.2 \\
10.2 \pm 1.8\end{array}$ & $47.3 \pm 2.0$ & $\begin{array}{l}0.860 \\
0.833\end{array}$ & 0.010 & $84.5 \pm 28.4$ & $\begin{array}{l}0.17 \\
0.19\end{array}$ & 0.037 & 23.2 \\
\hline OMM-1 (800-204,800) & $\begin{array}{l}5.8 \pm 0.9 \\
5.4 \pm 0.7\end{array}$ & $37.5 \pm 3.0$ & $\begin{array}{l}0.521 \\
0.557\end{array}$ & 0.042 & $14.1 \pm 2.6$ & $\begin{array}{l}0.30 \\
0.30\end{array}$ & 0.024 & 21.3 \\
\hline \multicolumn{9}{|l|}{ Cutaneous melanoma } \\
\hline MelSK28 (200-6,400) & $\begin{array}{l}26.7 \pm 1.3 \\
26.0 \pm 1.8\end{array}$ & $16.9 \pm 1.2$ & $\begin{array}{l}0.155 \\
0.115\end{array}$ & 0.053 & $3.3 \pm 0.6$ & $\begin{array}{l}0.59 \\
0.66\end{array}$ & 0.029 & 5.3 \\
\hline Bowes (100-12,800) & $\begin{array}{l}28.7 \pm 6.0 \\
26.7 \pm 5.9\end{array}$ & $18.5 \pm 0.3$ & $\begin{array}{l}0.353 \\
0.332\end{array}$ & 0.114 & $3.7 \pm 1.2$ & $\begin{array}{l}0.34 \\
0.36\end{array}$ & 0.062 & 5.7 \\
\hline
\end{tabular}

Data in \pm expressions are the mean \pm SEM. Eff., efficiency.

* Range of cell number plated per well.

+ Single-dose data.

‡ Data for two equal fractions with a time interval of 5 hours.

day. After irradiation, cells were incubated for colony formation. Slowgrowing cell lines (92-1) were incubated for 21 days instead of the standard 7 days (OCM-1, MelSK28, Bowes) or 14 days (Mel 202, OMM 2-2, OMM 2-3, OMM 2-6, Mel 270, OMM-1) to achieve sufficient colony formation.

Once the colonies reached an appropriate size they were fixed and counted, as published previously. ${ }^{6}$

\section{Data Analysis}

Cell survival curves were obtained for each cell line by analyzing the surviving fractions with the linear quadratic (LQ) model, as described in detail previously. ${ }^{6}$ For both single-dose and split-dose irradiations cell survival curves were averaged from at least three repeat experiments per cell line and with two different cell concentrations per dose point (Table 1). The $\alpha$-coefficients and the $\mathrm{SF}_{2}$ were calculated as estimates of the intrinsic radiosensitivity. Along similar lines, $\beta$-coefficients, which represent the capacity for repair of sublethal DNA damage, were calculated. Both the $\alpha$ - and $\beta$-components are cell- and tissue-specific and were used to derive the $\alpha / \beta$ ratio, the dose at which the contribution of the linear and the quadratic component are equal. Low $\alpha / \beta$ ratios $(<5$ Gy) provides a "curvy" cell survival curve for radiosensitive cells, with a relatively low $\alpha$-component, whereas higher $\alpha / \beta$ ratios give less curvy cell survival curves, indicative of cells with a relatively high $\alpha$-component. In addition, cells displaying low $\alpha / \beta$ ratios are spared by dose fractionation, whereas opposite effects are seen in cells with high $\alpha / \beta$ ratios

For very steep cell survival curves representing radiosensitive cells, the correspondingly low $\alpha$-component and $\mathrm{SF}_{2}$ dominate these curves, which makes it difficult to establish reliable $\beta$-coefficients. In such cases large $\beta$-components can be overlooked. ${ }^{12,15} \mathrm{~A}$ low plating efficiency would hamper the analysis even further, because of the small dose range for which cell survival could be measured. ${ }^{15}$ To overcome this problem, the use of the split-dose method provides a much more reliable estimate for the $\beta$-component. Based on the LQ-model it is predicted that the survival recovery ratio, the ratio of split-dose and single-dose cell survival, increases progressively with dose per fraction. ${ }^{16}$ There is a linear relationship between the recovered ratio and the dose per fraction $d$, calculated as: recovered ratio $(R R)=$ $\exp \left(2 \beta d^{2}\right)$ which converts into $\ln (R R)=2 \beta d^{2}$.

In this formula, $d$ is equal doses per fraction in a split-dose experiment-a split of $d+d$ (i.e., $1+1 \mathrm{~Gy}, 2+2 \mathrm{~Gy}$, etc.). The slope of this linear relationship provides an estimate of the $\beta$-component, termed $\beta_{\mathrm{RR}}$, which is derived independent of the $\alpha$-component. It was argued that at least four different dose levels were required for a proper estimate of the slope of this linear relationship. ${ }^{17}$ In this study, all split-dose experiments were performed in a standard manner at six different dose levels. The $\beta_{\mathrm{RR}}$ values presented in Table 1 are averages of at least three independent experiments per cell line with two different cell concentrations per experiment.

\section{Sulforhodamine B Assay}

The cell-doubling times were determined with the sulforhodamine B (SRB) assay, which is a colorimetric and nondestructive assay. ${ }^{18}$ Cells were grown at $37^{\circ} \mathrm{C}$ in 96-well plates with lanes of eight wells containing cell concentrations of 100, 250, 500, 1000, 2500, and 5000 cells/mL and $200 \mu \mathrm{L}$ medium/conditioned medium (1:1 vol/vol) per well. For each consecutive day, excluding Sundays, up to 7 days a separate plate was used. In each plate a lane of eight wells with medium only acted as the control. At harvest the medium was removed and cells were washed three times with distilled water. Cells were fixed with $10 \%$ trichloroacetic acid (TCA) solution for 1 hour at $4^{\circ} \mathrm{C}$, using $200 \mu \mathrm{L}$ per well. The plates were washed five times with distilled water, air dried overnight and kept at $4^{\circ} \mathrm{C}$. All plates were stained simultaneously for 2 hours adding $50 \mu \mathrm{L}$ per well of a $0.4 \%$ SRB solution in $1 \%$ acetic acid. Plates were washed five times in $1 \%$ acetic acid to remove unbound SRB. Per well $150 \mu \mathrm{L}$ Tris $(10 \mathrm{mmol} / \mathrm{L})$ was added and kept overnight at room temperature to dissolve the bound SRB. The following day, the optical density of the dye was measured in each well at $540 \mathrm{~nm}$ using a spectrophotometer (Bio-Rad, Hercules, CA). For each lane of eight wells, the optical density was averaged, omitting the highest and lowest value and subtracting the averaged control value. For each cell concentration the logarithmic values for the mean optical densities, expressed in arbitrary units and plotted as a function of time, gave straight lines. In a statistical analysis program 

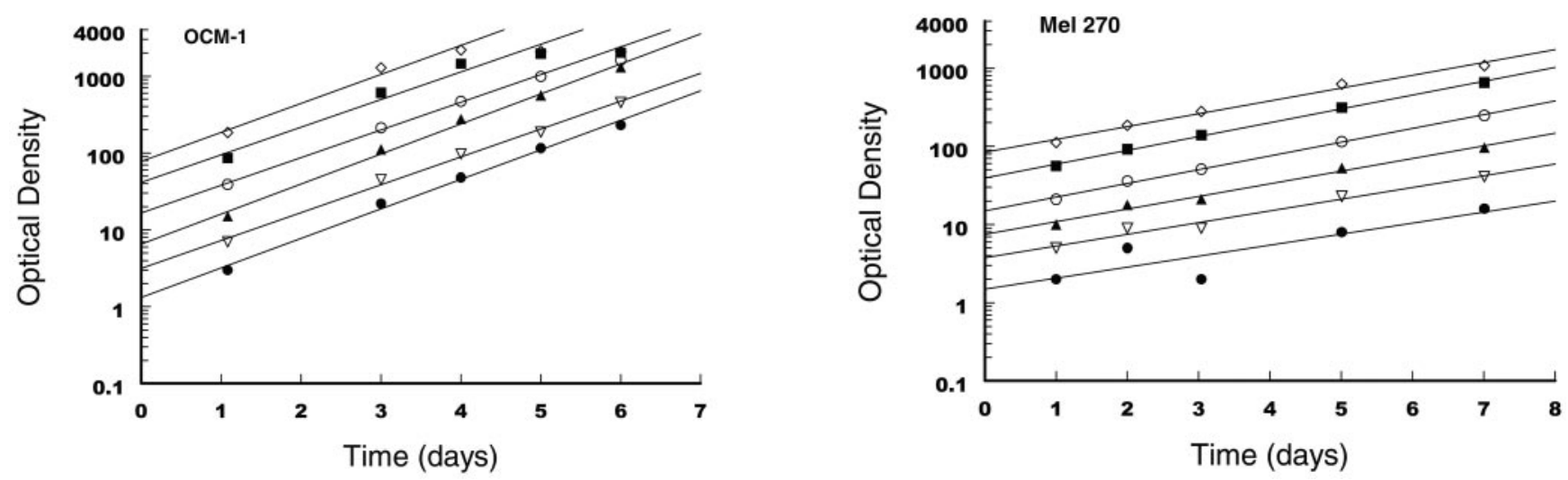

FiguRE 1. Growth curves for fast- and slow-growing cell lines (OCM-1 and Mel 270, respectively), obtained with the SRB assay. The slope of the curves is an estimate for the cell-doubling time. Increasing cell concentrations of $100(\bullet), 250(\nabla), 500(\boldsymbol{\Delta}), 1000(\bigcirc), 2500(\square)$, and $5000 \mathrm{cells} / \mathrm{mL}$ $(\diamond)$ were used. Cells were cultured in standard medium in the presence of conditioned medium (1:1 vol/vol).

(SlideWrite Plus; Advanced Graphics Software, Inc., Encinitas, CA), linear regression analysis was used for computer fitting of lines to the data points. Examples of optical densities as a function of time are presented in Figure 1. From the slopes of these lines, the cell-doubling time was calculated. Data for the lowest cell concentration were occasionally unreliable, producing lines with very shallow slopes, indicating a very slow cell growth. For the highest cell concentrations and the longer growth periods, arbitrary units in excess of 2000 were ignored, because it appeared to be the maximum reliable value in this assay. Beyond this value, cell growth was not logarithmic anymore and diminished because of too high cell densities in the wells, as seen in Figure 1 for OCM-1. Growth curves for the high cell concentrations based on only two or three time points were ignored. Values for the slopes of the growth curves from the intermittent cell concentrations were averaged and used to calculate a cell-doubling time for each experiment. The overall cell-doubling time for each cell line was an average obtained from at least three independent experiments.

\section{Results}

\section{Cell-Doubling Time}

The cell-doubling times for the uveal and cutaneous melanomas are presented in Table 1 . They range from 16.9 hours (MelSK28) to 47.3 hours (92-1). Examples of growth curves for fast- and slow-growing cell lines (OCM-1 and Mel 270, respectively) are presented in Figure 1. The short doubling times for some of these cell lines justified a short attachment period after plating before irradiation commenced. The short doubling times for some of these cell lines could have influenced the outcome of dose fractionation because of cell growth between application of fractions. For the fast-growing cell lines no significant cell growth was determined with the SRB assay within 6 hours after plating (data not shown).

\section{Plating Efficiency}

The plating efficiencies, as obtained from the surviving fractions after a dose of $0 \mathrm{~Gy}$, ranged from 5.4\% (OMM-1) to $43.1 \%$ (OMM 2-2) with no significant differences in cell concentration for both single and fractionated doses $(P>0.16)$. Hence, for each cell line data obtained for the two consecutive cell concentrations were combined. Also the plating efficiencies between the single and fractionated doses did not differ significantly $(P>0.38$; Table 1$)$.

\section{Cell Survival Curve Parameters}

Cell survival curves after single and fractionated doses are presented in Figure 2 for the uveal and cutaneous melanomas.
The parameters associated with these survival curves are presented in Table 1 . A wide range of $\alpha$-coefficients was found after single doses with very high and low values for OCM-1 cells $\left(0.153 \mathrm{~Gy}^{-1}\right)$ and for $92-1$ cells $\left(0.860 \mathrm{~Gy}^{-1}\right)$, respectively. Estimates for the $\alpha$-coefficients, indicative of intrinsic radiosensitivity, are reflected in the $\mathrm{SF}_{2}$, with high values for radioresistant cell lines and lower values for the more radiosensitive cell lines. After single doses, the $\beta$-coefficients ranged from 0.027 to $0.053 \mathrm{~Gy}^{-2}$, except for OMM 2-2 cells and the cutaneous melanoma Bowes cells, which produced much larger $\beta$-coefficients $\left(\sim 0.10 \mathrm{~Gy}^{-2}\right.$; Table 1$)$ indicating less efficient repair of DNA damage. This resulted in low $\alpha / \beta$ ratios of 3.5 to 4.7 Gy (OCM-1, OMM 2-2, SK28, and Bowes) and higher $\alpha / \beta$ ratios $(>8.8 \mathrm{~Gy})$ for the other primary and metastatic uveal melanomas. The exception was cell line 92-1 with a large $\alpha$-component of $0.86 \mathrm{~Gy}^{-1}$, whereas the $\beta$-component was very low, resulting in a high $\alpha / \beta$ ratio of $84.5 \mathrm{~Gy}$. The low $\mathrm{SF}_{2}$ indicates that this cell line is very radiosensitive.

As expected, after split-dose irradiation the $\alpha$-components (initial DNA damage) remained very similar to those obtained after single doses with only minor deviations of $\pm 10 \%$. For cell lines Mel270 and MelSK28, larger deviations of $+15.4 \%$ and $+25.5 \%$, respectively, were obtained for the $\alpha$-component. As expected, the $\mathrm{SF}_{2}$ increased after split-dose irradiation for all but one cell line, OMM-1. This increment in $\mathrm{SF}_{2}$ is a reflection of repair of sublethal DNA damage between application of the two fractions.

The alternative method for obtaining a more accurate estimate for the $\beta$-component independent of the $\alpha$-component, as reported by Peacock et al., ${ }^{15,17}$ resulted in $\beta_{\mathrm{RR}}$ values similar to those obtained with single-dose survival curves for most of the cell lines (Table 1). Only for cell lines OMM 2-2, 92-1, and OMM-1, the $\beta_{\mathrm{RR}}$ values deviated substantially, which resulted in much higher (OMM 2-2 and OMM-1) or lower $\alpha / \beta$ ratios (92-1).

\section{Discussion}

The single-dose data, presented in this article on the radiosensitivity for primary and metastatic human uveal melanoma cell lines, are more refined than those published earlier. ${ }^{6}$ These earlier results could have been influenced by a confounding factor such as cell growth during overnight attachment. The short cell-doubling time for some of the cell lines indicated that a short attachment period of 2 hours before commencement of irradiation was more appropriate than overnight attachment. Apart from reduced plating efficiencies for nearly all cell lines, this shorter attachment period also produced much higher 

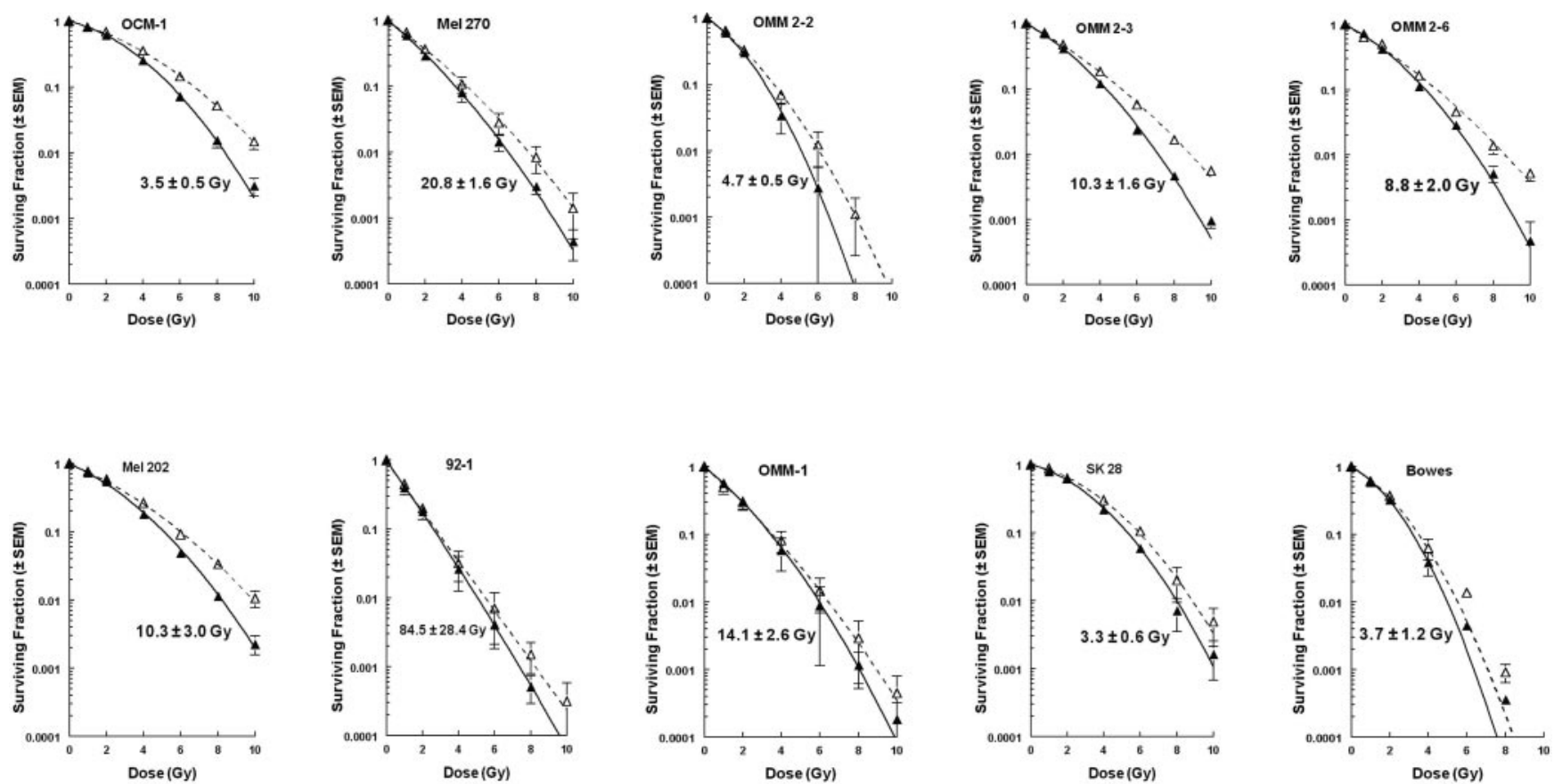

Figure 2. Cell survival curves for various primary (OCM-1, Mel 270, Mel 202, 92-1) and metastatic (OMM 2-2, OMM 2-3, OMM 2-6, OMM-1) human uveal melanomas in comparison with cutaneous melanomas (MelSK28, Bowes) after single doses of X-rays (solid lines) and split-dose irradiation involving two equal fractions with an interfraction interval of 5 hours (dotted lines). Cells were cultured in standard medium in the presence of conditioned medium $(1: 1 \mathrm{vol} / \mathrm{vol})$. If standard errors are not present, they fall within the symbol. Data indicate $\alpha / \beta$ ratios ( \pm SEM).

$\alpha$-components for OCM-1 cells and Bowes cells, whereas for the cell types OMM 2-2, OMM 2-3, OMM 2-6, and MelSK28 the $\beta$-coefficient increased. This resulted in low $\alpha / \beta$ ratios of approximately $3.5 \mathrm{~Gy}$ for the fast-growing cell lines. In this study, better estimates for the single-dose cell survival curves of 92-1 cells and OMM-1 cells could be obtained, because of higher cell concentrations at the higher dose points and a longer postradiation incubation time of 21 days (92-1). This resulted in more reliable data at higher doses, explaining the differences in parameters with previously published data for these two cell lines. $^{6}$

Cells displaying a low $\alpha / \beta$ ratio, which is indicative of a sparing effect after dose fractionation, require large doses per fraction for effective tumor treatment. In this instance little benefit in therapeutic ratio was seen, because the late-responding normal tissues also displayed low $\alpha / \beta$ ratios in the range of 1 to $5 \mathrm{~Gy}$. For cell lines with higher $\alpha / \beta$ ratios (>6 Gy), conventional doses per fraction of 2 Gy should provide therapeutic gain with an increased probability of tumor cure and sparing of late-responding normal tissues.

In this study, cell lines Mel270, 92-1, and OMM-1 displayed low plating efficiencies and high $\alpha$ values after single-dose irradiation, and therefore estimates for the $\beta$-coefficient could be inaccurate. ${ }^{12,15}$ The $\beta_{\mathrm{RR}}$ values for all cell lines displayed a narrow range of $0.024 \mathrm{~Gy}^{-2}$ (OMM-1) to $0.047 \mathrm{~Gy}^{-2}$ (OMM 2-2), which was much smaller than that obtained from analysis of the single-dose cell survival curves (Table 1). It appeared that for cell lines OMM 2-2, 92-1, and OMM-1 the $\beta_{\mathrm{RR}}$ values differed substantially from those obtained after single-dose irradiation, but were now within the range of the other cell lines. A much lower $\beta_{\mathrm{RR}}$ value was unexpectedly also found for OMM 2-2 cells compared with the original $\beta$-component after single-dose irradiation. Only for Bowes cells was the $\beta_{\mathrm{RR}}$ value $\left(0.0622 \mathrm{~Gy}^{-2}\right)$ outside this range, but it was approximately half the value obtained from the single-dose cell survival curve. This had an effect on the new $\alpha / \beta_{\mathrm{RR}}$ ratios with that for OMM 2-2 cells in the same range as for the other metastatic cell lines
OMM 2-3 and OMM 2-6. All three cell lines derived from the same primary melanoma Mel 270 (Table 1). Also for cell line 92-1 and OMM-1, the $\alpha / \beta_{\mathrm{RR}}$ ratios changed to approximately 22 Gy. The new $\alpha / \beta_{\mathrm{RR}}$ ratios for the cutaneous melanomas increased to approximately $5.5 \mathrm{~Gy}$.

For a number of human tumor cell lines, a linear relationship between $\ln (\mathrm{RR})$ and fraction dose $(d)$, as predicted by the LQ model, has been demonstrated, ${ }^{15,17,19,20}$ which resulted in a $\beta_{\mathrm{RR}}$ independent of the $\alpha$-component. It was also argued that an estimate of the $\alpha$-component could be obtained independent of the $\beta$-component by low-dose irradiation. ${ }^{15,17}$ At our institute, facilities for low-dose irradiation were not available, and hence an estimate for an independent $\alpha$-component could not be achieved.

The $\beta_{\mathrm{RR}}$ values are in the normal range for tumor cell lines and differ only by a factor of 2 . This indicates that the capacity for repair of sublethal DNA damage is fairly constant for all cell lines investigated. This implies that the variations in radiosensitivity of these melanoma cell lines are more determined by the $\alpha$-components-that is, the intrinsic radiosensitivity-and to a lesser extent by contributions of sublethal DNA damage repair. This has implications for clinically relevant dose fractionation schedules, because cell types OCM-1, Mel 202, and MelSK28 with low $\alpha$-components and high $\mathrm{SF}_{2}$ s would necessitate relatively large doses of approximately $8 \mathrm{~Gy}$ in five fractions for effective elimination of a tumor containing approximately $10^{9}$ cells. In contrast, for cell type 92-1, doses of approximately $4 \mathrm{~Gy}$ in five fractions should be sufficient for effective eradication, with a beneficial effect of limiting adverse normal tissue toxicity.

In low-dose-rate (LDR) brachytherapy, cell survival is entirely determined by the $\alpha$-component-that is, the intrinsic radiosensitivity, due to repair of sublethal DNA damage during the long exposure times and hence the absence of the $\beta$-component. For the two most extreme $\alpha$-components in this study, elimination of $10^{9}$ cells of tumor type OCM-1 would require approximately $135 \mathrm{~Gy}$, whereas tumor type 92-1 would require 
only approximately $24 \mathrm{~Gy}$. With a dose rate of approximately $1 \mathrm{~Gy} /$ hour this indicates an exposure time of approximately 5.6 days for OCM-1 cells, whereas cells of tumor type 92-1 would be eliminated in 1 day.

Caution should be used in translating these in vitro data directly into clinical practice. However, studies have shown that for many tumor cell lines, in vitro data and especially parameters related to the initial part of the cell survival curve, such as the $\alpha$-component and $\mathrm{SF}_{2}$, seem to correlate with the clinical radioresponsiveness of human tumors. ${ }^{21}$ That the radiosensitivity of these uveal melanomas is mainly determined by the intrinsic radiosensitivity should encourage a study on specific morphologic and histologic tumor markers, which could be applied in the clinical situation without tumor biopsy. Based on these morphologic markers, tumor classification would become a possibility, leading to more individualized dose fractionation schedules.

\section{Acknowledgments}

The authors thank Anita Siewert for advice on the SRB assay and Henk B. Kal for fruitful discussions and critical comments on the manuscript.

\section{References}

1. Char DH, Kroll SM, Castro J. Ten-year follow-up of helium ion therapy for uveal melanoma. Am J Ophthalmol. 1998;125:81-89.

2. Finger PT. Radiation therapy for choroidal melanoma. Surv Ophthalmol. 1997;42:215-232.

3. Logani S, Cho AS, Ali BH, et al. Single-dose compared with fractionated-dose radiation of the OM431 choroidal melanoma cell line. Am J Ophthalmol. 1995;120:506-510.

4. Logani S, Cho AS, Su LD, et al. Effects of gamma radiation on the OM431 human ocular melanoma cell line. Exp Eye Res. 1995;60: 603-605.

5. Soulières D, Rousseau A, Tardif M, et al. The radiosensitivity of uveal melanoma cells and the cell survival curve. Graefes Arch Clin Exp Ophthalmol. 1995;233:85-89.

6. van den Aardweg GJMJ, Naus NC, Verhoeven AAC, de Klein A, Luyten GPM Cellular radiosensitivity of primary and metastatic human uveal melanoma cell lines. Invest Ophthalmol Vis Sci. 2002; $43: 2561-2565$.

7. Barendsen GW. Dose fractionation, dose rate and iso-effect relationships for normal tissue responses. Int J Radiat Oncol Biol Phys. 1982;11:1981-1997.
8. Douglas BG, Fowler JF. The effect of multiple small doses of $x$ rays on skin reactions in the mouse and a basic interpretation. Radiat Res. 1976;66:401-426.

9. Thames HD, Withers HR, Peters LJ, Fletcher GH. Changes in early and late radiation responses with altered dose fractionation: implications for dose-survival relationships. Int J Radiat Oncol Biol Phys. 1982;8:219-226.

10. Brock WA, Baker FL, Peters LJ. Radiosensitivity of human head and neck squamous cell carcinomas in primary culture and its potential as a predictive assay of tumor radiocurability. Int J Radiat Biol. 1989;56:751-760.

11. Davidson SE, West CM, Roberts SA, Hendry JH, Hunter RD. Radiosensitivity testing of primary cervical carcinoma: evaluation of intra- and inter-tumour heterogeneity. Radiother Oncol. 1990;18: 349-356.

12. Steel GG, Peacock JH. Why are some human tumours more radiosensitive than others? Radiother Oncol. 1989;15:63-72.

13. Elkind MM, Sutton H. Radiation response of mammalian cells grown in culture: I. Repair of X-ray damage in surviving Chinese hamster cells. Radiat Res. 1960;13:566-593.

14. Steel GG, Clonogenic cells and the concept of cell survival. In: Steel GG, Ed. Basic Clinical Radiobiology. London: Edward Arnold Publishers; 1993:28-39.

15. Peacock JH, Cassoni AM, McMillan TJ, Steel GG. Radiosensitive human tumour cell lines may not be recovery deficient. Int $J$ Radiat Biol. 1988;54:945-953.

16. Thames HD. An "incomplete-repair" model for survival after fractionated and continuous irradiations. Int J Radiat Biol 1985;47: 319-339.

17. Peacock JH, Eady JJ, Edwards SM, McMillan TJ, Steel GG. The intrinsic alpha/beta ratio for human tumour cells: is it a constant? Int J Radiat Biol. 1992;61:479- 487.

18. Skehan P, Storeng R, Scudiero D, et al. New colorimetric cytotoxicity assay for anticancer-drug screening. J Natl Cancer Inst. 1990; 82:1107-1112.

19. Holmes A, Mc Millan TJ, Peacock JH, Steel GG. The radiation dose-rate effect in two human neuroblastoma cell lines. $\mathrm{Br} \mathrm{J}$ Cancer. 1990;62:791-795.

20. Yang X, Darling JL, McMillan TJ, Peacock JH, Steel GG. Radiosensitivity, recovery and dose-rate effect in three human glioma cell lines. Radiother Oncol. 1990;19:49-56.

21. Malaise EP, Fertil B, Chavaudra N, Guichard M. Distribution of radiation sensitivities for human tumor cells of specific histological types: comparison of in vitro to in vivo data. Int J Radiat Oncol Biol Phys. 1986;12:617-624. 